\title{
Intensity of parasitic mite infection decreases with hibernation duration of the host snail
}

\author{
E. M. HAEUSSLER ${ }^{1}$, J. PIZÁ ${ }^{2}$, D. SCHMERA ${ }^{1}$ and B. BAUR ${ }^{1}$ \\ ${ }^{1}$ Department of Environmental Sciences, Section of Conservation Biology, University of Basel, St Fohanns-Vorstadt 10, \\ CH-4056 Basel, Switzerland \\ ${ }^{2}$ Laboratorio de Zoología de Invertebrados 1, Departmento de Biología, Bioquímica y Farmacia, Universidad Nacional del \\ Sur, San Fuan 670, (8000) Bahía Blanca, Argentina
}

(Received 24 November 2011; revised 2 February 2012; accepted 5 February 2012; first published online 23 March 2012)

SUMMARY

Temperature can be a limiting factor on parasite development. Riccardoella limacum, a haematophagous mite, lives in the mantle cavity of helicid land snails. The prevalence of infection by R. limacum in populations of the land snail Arianta arbustorum is highly variable (0-78\%) in Switzerland. However, parasitic mites do not occur in host populations at altitudes of $1290 \mathrm{~m}$ or higher. It has been hypothesized that the host's hibernation period might be too long at high elevations for mites and their eggs to survive. To test this hypothesis, we experimentally infected snails and allowed them to hibernate at $4{ }^{\circ} \mathrm{C}$ for periods of $4-7$ months. Winter survival of host snails was negatively affected by $R$. limacum. The intensity of mite infection decreased with increasing hibernation duration. Another experiment with shorter recording intervals revealed that mites do not leave the host when it buries in the soil at the beginning of hibernation. The number of mites decreased after 24 days of hibernation, whereas the number of eggs attached to the lung tissue remained constant throughout hibernation. Thus, R. limacum survives the winter in the egg stage in the host. Low temperature at high altitudes may limit the occurrence of R. limacum.

Key words: Arianta arbustorum, Riccardoella limacum, winter survival, population growth, climate warming.

\section{INTRODUCTION}

Parasites are known to influence the life history, behaviour and demography of host populations (Agnew et al. 2000; Moore, 2002; Poulin, 2007). Hosts in turn have evolved a wide range of adaptations to prevent initial parasite infection and subsequent proliferation. These adaptations range from the extraordinary complexity of antigenspecific cell-mediated responses found in vertebrates to the simpler humoral and cell-mediated responses of invertebrates, through barrier mechanisms, to behaviour that may reduce the likelihood of an individual becoming exposed to a parasite or that may act to control infections once they have been developed (Sheldon and Verhulst, 1996; SchmidHempel, 1998; Moore, 2002). In parasite-host systems with invertebrate hosts and relatively large parasites, the reproduction of parasites highly depends on the condition of the host because parasites consume a high proportion of the host resources (Seppälä et al. 2008). For example, starvation in Daphnia magna (STRAus 1820) reduces the spore load and prevalence of the microsporidian gut parasite Glugoides intestinalis (CHATTON 1907), but causes also

\footnotetext{
* Corresponding author: Department of Environmental Sciences, Section of Conservation Biology, University of Basel, St Johanns-Vorstadt 10, CH-4056 Basel, Switzerland. Tel: +41612670846. Fax: +4161267 08 32. E-mail: ellen.haeussler@unibas.ch
}

an increased host mortality (Pulkkinen and Ebert, 2004).

The conditions for parasites may also be altered during the hibernation of ectothermic hosts. This is of particular interest when the duration of the hibernation period varies among host populations. If the hibernation of the host is extremely long, then the host-parasite dynamics might be disturbed. So far, the influence of hibernation on the host-parasite dynamic has been poorly studied in invertebrates (Tyler and Jones, 1974; Callait and Gauthier, 2000; Moore, 2002; Schüpbach and Baur, 2010a). In land snails, hibernation is an overwintering strategy characterized by a reduction of feeding, locomotion and reproduction (Ansart et al. 2001). Many species bury in the soil or remain in protected places and close the shell aperture with the epiphragm, a mucoproteinacaeous membrane. The metabolism slows down, and a reduction of oxygen consumption and rate of water loss occurs (Banhart and McMahon, 1988; Ansart et al. 2001, 2002).

Riccardoella limacum (Schrank 1776) is an ectoparasite mite of terrestrial gastropods (Fain and Van Goethem, 1986). The mite feeds on blood in the mantle cavity of its host (Baker, 1970a). It reduces the activity and growth rate of the gastropod Cornu aspersum (MülLER 1774) delaying reproductive development (Graham et al. 1996). In the land snail Arianta arbustorum (LinNaEus 1758), parasite infection reduced the activity of individuals and their 
reproductive output, and decreased winter survival (Schüpbach and Baur, 2008a). Host survival during hibernation decreased with increasing parasite load and differed among families, but was not affected by snail size (Schüpbach and Baur, 2010b). The mites are transmitted through physical contact among the hosts (Baur and Baur, 2005), via mucus trails of the host snail or indirectly via soil (Schüpbach and Baur, 2008b). It is unknown, however, how long the parasites can survive in the soil. Natural snail populations vary widely in prevalence of mite infection (0-78\% in 11 populations; Baur and Baur, 2005). However, parasitic mites have not been found in snail populations situated at elevations of $1290 \mathrm{~m}$ or higher. It has been hypothesized that the host's hibernation period might be too long at high elevations for mites and their eggs to survive (Baur and Baur, 2005).

The aim of our study was to investigate the influence of hibernation duration in experimentally infected host snails on the intensity of infection and host survival. In particular, we addressed the following questions. (1) Is host survival affected by the intensity of infection and hibernation duration? (2) Does the intensity of parasite infection decrease with hibernation duration of the host? (3) Do parasitic mites leave the host at the beginning of hibernation? (4) Can parasitic mites and/or their eggs survive the winter ( 7 months) in the soil?

\section{MATERIALS AND METHODS}

\section{Study species}

The mite Riccardoella limacum is a monoxenous parasite that lives in the mantle cavity of land snails (Fain and van Goethem, 1986). The total life cycle of $R$. limacum lasts 19-23 days at temperatures of $20-25^{\circ} \mathrm{C}$. Female mites lay their eggs in the respiratory tissue of the host. After 3 nymphal stages, mites develop to sexually mature males and females of 0.4 mm body size (Baker, 1970b).

Arianta arbustorum is a simultaneously hermaphroditic land snail common in moist habitats of northwestern and central Europe, living at elevations of up to $2700 \mathrm{~m}$ above sea level (Kerney and Cameron, 1979). The snail has determinate growth (shell breadth of adults 17-24 mm; Baur, 1984). Individuals become sexually mature at $2-4$ years old and adults live for another 3-4 years (Baur and Raboud, 1988). Arianta arbustorum mates repeatedly in the course of a reproductive season (Baur, 1988).

\section{Experiment 1: Host survival and intensity of infection during hibernation}

We randomly collected 240 adult individuals of A. arbustorum in a parasite-free population on an alpine pasture with scattered scree, near Gantrisch,
$20 \mathrm{~km}$ south of Bern, Switzerland $\left(46^{\circ} 42^{\prime} 19^{\prime \prime} \mathrm{N}, 7^{\circ} 26^{\prime}\right.$ $42^{\prime \prime} \mathrm{E}$; altitude $1810 \mathrm{~m}$ ) on 29 August 2010. The snails were kept individually in transparent plastic beakers $(6.5 \mathrm{~cm}$ in diameter, $8 \mathrm{~cm}$ deep) on moist soil mixed with powdered limestone under a light/dark cycle of $16: 8 \mathrm{~h}$ and a constant temperature of $19^{\circ} \mathrm{C}$. The soil was obtained from the snails' site of origin. The beakers were cleaned 1-2 times per week and a diet of fresh lettuce was provided ad libitum.

After 4 weeks, we experimentally infected half of the snails with $R$. limacum (the other half served as controls). Mites were obtained from parasite-infected A. arbustorum collected near Nuglar, $15 \mathrm{~km}$ southeast of Basel $\left(47^{\circ} 28^{\prime} 42^{\prime \prime} \mathrm{N}, 7^{\circ} 41^{\prime} 38^{\prime \prime} \mathrm{E}\right.$; altitude $\left.434 \mathrm{~m}\right)$. We transferred 6 adult mites to the soft body of an uninfected snail using a small, moistened paintbrush. When the transmitted mites had entered the pulmonary cavity, we put the newly infected snail back into its beaker (Schüpbach and Baur, 2010a). Mite intensity of experimentally infected snails was in the range of infection intensities recorded in natural populations $(0 \cdot 3-8 \cdot 0$ mites/snail; Baur and Baur, 2005). Transmitted mites were allowed to reproduce for 6 weeks on their host i.e. 2 mite generations under the conditions described above (Graham et al. 1996). We measured the size of each snail (shell diameter) to the nearest $0 \cdot 1 \mathrm{~mm}$ using vernier callipers.

Infected snails and those of the control group were randomly assigned to all 4 groups of about 30 individuals that were allowed to hibernate for 4, 5, 6 or 7 months. Hibernation occurred at $4{ }^{\circ} \mathrm{C}$, in darkness, in beakers lined with $4 \mathrm{~cm}$ of moist soil. These conditions are similar to those of hibernating snails buried in the field (Baur, 1994). Hibernating snails (infected and uninfected) were checked every second week to record dead animals. After a hibernation period of 4, 5, 6 or 7 months, infected and uninfected snails were kept again under the same conditions as in the pre-hibernation period for 3 weeks (see above). Infected and uninfected snails did not differ in shell size at the beginning of the experiment (ANOVA, $\mathrm{F}_{1,232}=0.552, P=0.458$ ) and individuals assigned to the 4 groups with different hibernation duration did not differ in shell size (ANOVA, $\mathrm{F}_{3,230}=0.027, P=0.994$ ).

We assessed the parasite load (= intensity of infection) of infected and control snails immediately prior to hibernation and in the 3 -week period after hibernation using a non-invasive screening method (Baur and Baur, 2005). The soft body and respiratory pore of each individual were carefully examined for mites using a binocular microscope. The intensity of parasites was expressed as the mean number of mites observed in 3 examinations on 3 different days (Baur and Baur, 2005). A snail was considered as infected if at least 1 mite could be detected during the 3 observations.

Three weeks after hibernation, the hosts were frozen for a posterior screening of mites in the lung 
tissue. Snails were fixed in $70 \%$ ethanol and dissected under a binocular microscope (Leica MZ8) to quantify the number of mites and eggs in the lung. To assess the potential effect of parasitic mites on the reproductive system of the host, we determined the dry mass of the albumen gland of each snail.

\section{Experiment 2: Short-term response of parasitic mites}

To examine whether parasitic mites leave the host at the beginning of the hibernation, we collected 81 adult individuals of $A$. arbustorum from a naturally infected population near Nuglar $\left(47^{\circ} 28^{\prime} 42^{\prime \prime} \mathrm{N}, 7^{\circ} 41^{\prime}\right.$ $38^{\prime \prime} \mathrm{E}$; altitude $434 \mathrm{~m}$ ) on 18 September 2010. The snails were kept individually in beakers (depth $8 \mathrm{~cm}$, diameter $6.5 \mathrm{~cm}$ ) lined with moist soil at $19{ }^{\circ} \mathrm{C}$ and a 16:8 light/dark cycle. The soil used was from the site Gantrisch, where no mites occur. We repeated the non-invasive parasite screening 5 times. After 19 days, 45 infected snails were randomly assigned to 7 groups each consisting of $6-8$ individuals. The groups did not differ in mean shell size $\left(\mathrm{F}_{6,38}=0 \cdot 016\right.$; $P=0.999)$ and parasite load $\left(\mathrm{F}_{6,38}=1.541 ; P=0 \cdot 191\right)$. The snails were allowed to hibernate as described above for periods of 0 (control), 4, 8, 12, 24, 48 or 72 days. After hibernation, snails of the corresponding group were frozen and the actual number of mites and eggs in the lung tissue was determined for each host as described above.

\section{Experiment 3: Mite survival in the soil}

To examine whether parasitic mites survive in the soil during the hibernation period of snails, beakers containing soil on which experimentally infected snails from Gantrisch $(n=34)$, natural infected snails from Nuglar $(n=26)$ or uninfected snails from Gantrisch ( $n=26$, control) had been maintained singly for 6 weeks, were transferred to hibernation conditions $\left(4^{\circ} \mathrm{C}\right.$, darkness), but without snails. After a period of 7 months, uninfected individuals of A. arbustorum from Gantrisch were placed singly in the beakers with the 3 soil treatments and kept under standard conditions $\left(19^{\circ} \mathrm{C}, 16: 8\right.$ dark/light cycle; as described above) for 3 months. After 3 months, snails were frozen and a posterior screening of mites and their eggs in the lung tissue was performed as described above.

\section{Statistical analysis}

Data analysis was performed using R Statistical Software (R Development Core Team, 2011). We used Generalized Linear Models (GLM) with binomial distribution to examine the effects of parasite infection (categorical predictor), hibernation duration and size of individual snails (both continuous predictors) on host survival (Exp. 1). The minimal adequate model was selected by Akaike
Information Criterion (AIC). We used linear models (LM) to test whether the intensity of mite infection changed with increasing duration of hibernation and with snail size as well as to examine whether the dry weight of the albumin gland $(\log (x+1)$-transformed) differed between infected and uninfected snails and was affected by hibernation duration and snail size. We used GLM with Poisson distribution to examine whether the numbers of mites and eggs found in the lung tissue of hosts were influenced by hibernation duration (Exp. 2).

\section{RESULTS}

\section{Experiment 1: Host survival and intensity of infection during hibernation}

Host survival was affected negatively by parasite infection but not by the duration of hibernation and the size of individual snails (Fig. 1). Statistical model selection removed the factors hibernation duration and shell size as well as the two-way interactions keeping only the factor parasite infection in the minimal adequate model (GLM, estimate $=-0.678$, S.E. $=0 \cdot 332, z=-2 \cdot 044, P=0 \cdot 041)$. Overall, 80 out of the 108 infected snails $(74 \cdot 1 \%)$ survived hibernation as did 107 of the $126(84.9 \%)$ uninfected snails. The intensity of infection prior to hibernation averaged 2.9 mites (range $0 \cdot 3-12 \cdot 0, \quad n=108$ ). Survival of host snails during hibernation tended to be negatively affected by the intensity of infection assessed prior to hibernation (GLM, estimate $=$ $-0 \cdot 783$, s.E. $=0 \cdot 425, z=-1 \cdot 841, P=0 \cdot 062)$.

The intensity of infection decreased with increasing hibernation duration (Fig. 2). Model selection removed the factor snail size and the two-way interaction keeping only the factor hibernation duration in the minimal adequate model (LM, estimate $=-0 \cdot 500$, s.E. $=0 \cdot 186, t=2 \cdot 688, P=0 \cdot 008)$. The decrease in parasite load, expressed by the difference between intensity of infection prior to hibernation and intensity of infection after hibernation, was $1 \cdot 5 \pm 0.4$ mites after 4 months $(n=22)$, mean \pm s.E., $2 \cdot 0 \pm 0 \cdot 3$ mites after 5 months $(n=19)$, $2 \cdot 3 \pm 0 \cdot 4$ mites after 6 months $(n=20)$, and $3 \cdot 1 \pm 0 \cdot 6$ mites after 7 months $(n=19)$.

The dry weight of the albumen gland, an estimate of the female reproductive capacity in the successive season, did not differ between infected and parasite-free host snails (LM, estimate $=0 \cdot 028$, S.E. $=0.218, t=0.129, P=0.898)$. Furthermore, the dry weight of the albumen gland was neither affected by hibernation duration (estimate $=-0 \cdot 068$, S.E. $=0.075, t=0.911, P=0.365)$ nor by snail size $(\mathrm{LM}, \quad$ estimate $=-0 \cdot 018, \quad$ S.E. $=0 \cdot 116, \quad t=0 \cdot 158$, $P=0 \cdot 875)$.

Considering exclusively infected host snails that survived, the detailed examination of the lung tissue 3 weeks after hibernation revealed a mean number 


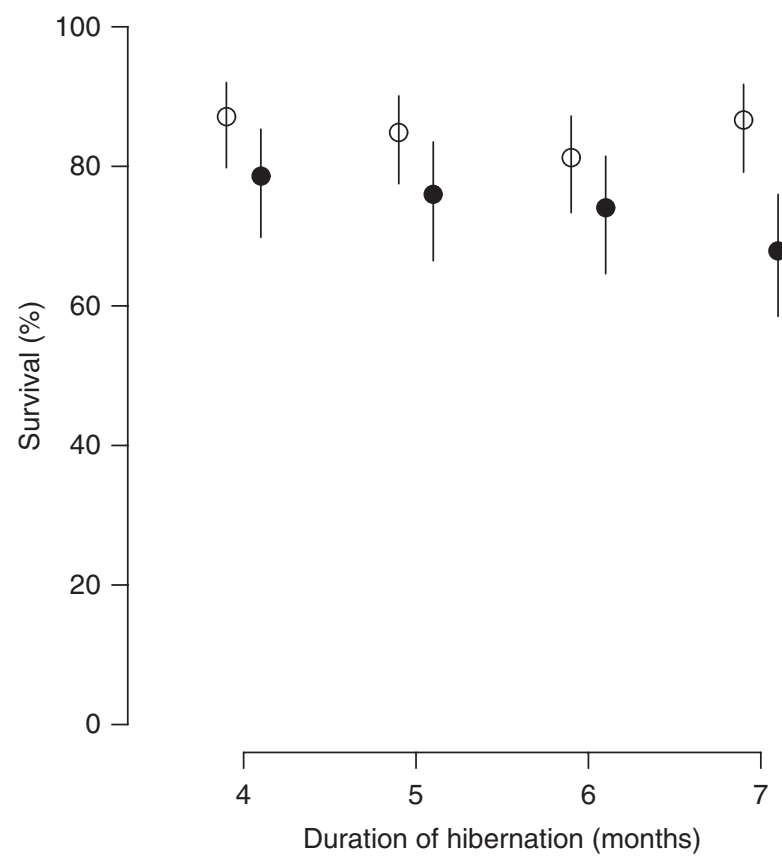

Fig. 1. Survival of infected (black dots) and uninfected (open dots) host snails in relation to hibernation duration. Whiskers represent standard errors based on binomial distributions. Sample sizes for infected snails were 28, 25, 27 and 28, those for uninfected snails were 32, 33, 32 and 30 .

of $10 \cdot 2$ mites (s.E. $=2 \cdot 0$, range: $0-77, n=80$ ) and of $8 \cdot 3$ eggs (s.E. $=1 \cdot 8$, range: $0-87, n=80$ ). The number of mites found in the lung was negatively affected by the hibernation duration of the host (GLM, estimate $=-0 \cdot 101$, s.E. $=0 \cdot 031, z=-3 \cdot 224, P=0 \cdot 001)$. However, the number of mite eggs was not influenced by hibernation duration (GLM, estimate $=-0 \cdot 035$, s.E. $=0 \cdot 034, z=-1 \cdot 010, P=0 \cdot 312)$.

\section{Experiment 2: Short-term response of parasitic mites}

Host snails kept under hibernation conditions for 0 (control), 4, 8, or 12 days did not differ in the number of mites and mite eggs found in the lung tissue (mites: ANOVA, $\mathrm{F}_{3,20}=1 \cdot 173, P=0 \cdot 345$; eggs: $\mathrm{F}_{3,20}=0 \cdot 054$, $P=0.983)$. This indicates that none or very few mites left their hosts at the beginning of hibernation. Consequently, data of host snails kept under hibernation conditions for 0-12 days were combined for further analyses. Host snails hibernating for different periods showed different numbers of mites (Fig. 3; ANOVA, $\mathrm{F}_{3,41}=2 \cdot 854, P=0 \cdot 048$ ). In contrast, the number of mite eggs found in the lung tissue did not change with increasing hibernation duration of the host snails (Fig. 3; $F_{3,41}=1 \cdot 206$, $P=0 \cdot 319)$.

\section{Experiment 3: Mite survival in the soil}

No parasitic mites and eggs were found in the lung tissue of originally parasite-free snails $(n=26)$ kept on

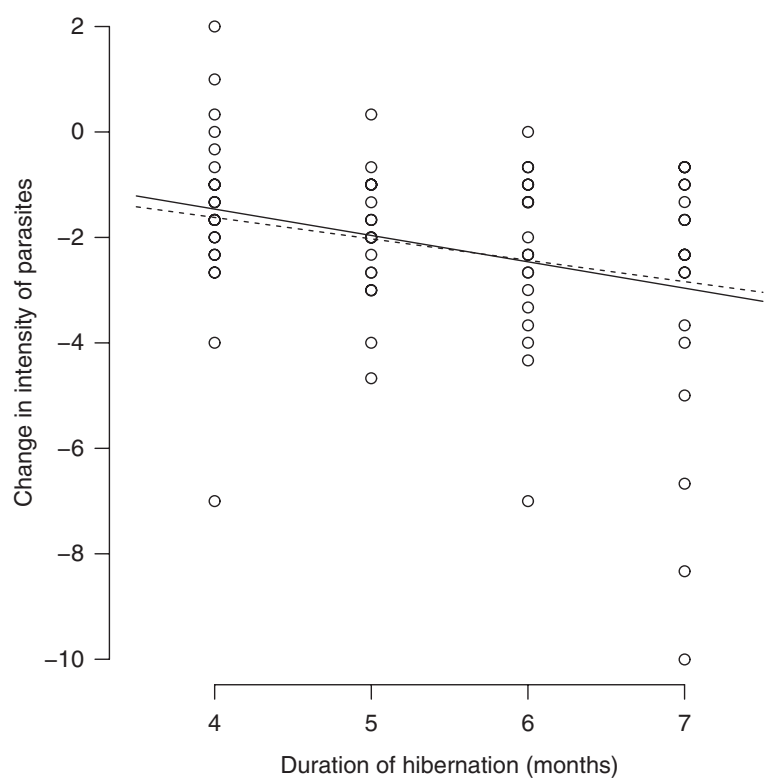

Fig. 2. Decrease in intensity of parasitic mites in relation to hibernation duration of the host snail Arianta arbustorum. Open dots represent single snails. The solid line represents the fitted linear model $\left(Y=-0 \cdot 500 X+0 \cdot 538 ; R^{2}=0 \cdot 085, n=80, P=0 \cdot 008\right)$, the dashed line the linear model including the zero point (no intercept: $Y=-0 \cdot 405 X ; R^{2}=0 \cdot 596, n=80$, $P<0 \cdot 001)$.

control soil for 6 weeks. Similarly, no parasitic mites and eggs were recorded in originally parasite-free snails $(n=26)$ kept on soil on which naturally infected snails from the population Nuglar had previously been maintained before the soil was stored at $4{ }^{\circ} \mathrm{C}$ for 7 months. However, 1 single mite egg but no adult mite was found in the lung tissue of one of the 34 originally parasite-free snails kept on soil on which experimentally infected snails from the population Gantrisch had previously been maintained before it was stored at $4{ }^{\circ} \mathrm{C}$ for 7 months. This indicates that mite survival in the soil might be very low during winter.

\section{DISCUSSION}

Our study provides experimental evidence that winter survival of the host snail $A$. arbustorum is negatively affected by $R$. limacum, but not by the size of the snails. Furthermore, the intensity of mite infection decreased with increasing hibernation duration of the host. Reduced winter survival has also been found in naturally infected individuals of $A$. arbustorum in 2 out of 3 populations (Schüpbach and Baur, 2008a). In experimentally infected A. arbustorum, mortality during hibernation was both influenced by the intensity of infection and family origin (Schüpbach and Baur, 2010a). Similarly, in the present study, host survival during the winter tended to be negatively affected by the intensity of infection. 


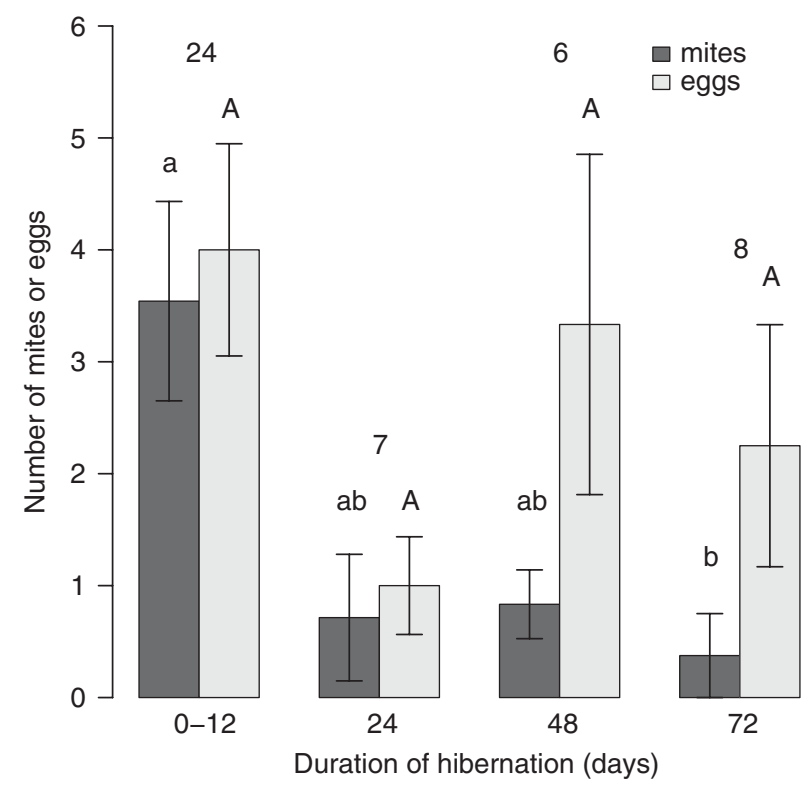

Fig. 3. Number of mites and eggs found in the lung tissue of the host snail Arianta arbustorum after hibernation periods of different lengths. Means \pm 1 s.E. are shown with sample size on the top of bars. Small letters (in mites) and capitals (in eggs) indicate significant differences between hibernation periods of different lengths.

Differences in winter survival of parasitized and parasite-free hosts may directly affect gene frequencies in the host population and thus influence the host-parasite co-evolution (Mitchell et al. 2005).

Any estimate of intensity of infection relies on the accuracy of the method used for counting the parasites. In our study organism, the non-invasive estimate could be influenced by uncertainties in the recognition of lightly infected animals. The dissection of snails with a careful examination of their lung epithelium is the most precise but also timeconsuming method, provided that the mites do not leave the freshly-killed host. We did not observe that mites left dead $A$. arbustorum, which were killed by freezing. However, apart from the ethical issue of killing animals, potential effects of parasite infection on the hosts can no longer be examined. These problems can be avoided by using non-invasive parasite screening methods. The non-invasive method used in this study is fairly accurate and its precision can further be improved by increasing the number of visual mite assessments (e.g. from 3 to 5 times, as done in Exp. 2), which is feasible in snails kept in controlled laboratory experiments (Baur and Baur, 2005).

Riccardoella limacum depends on its host to complete the life cycle (Baker, 1970b). Food uptake and reproduction are only possible in the mantle cavity of the host (Baker, 1970a). Mites are frequently transmitted during courtship and mating of A. arbustorum. The parasites move over the soft body of the snail and switch to the new host. Furthermore, $R$. limacum has been found to be successfully transmitted via soil without physical contact (Schüpbach and Baur, 2008b). Experiments showed that the blind mites use fresh mucus trails of snails to locate new hosts (Schüpbach and Baur, 2008b). In this way they also infect juvenile snails. Baker (1970a) studied the off-host survival of $R$. limacum and found that mites kept in culture cells survived for 8 days without food supply at room temperature. In moist soil kept at $19^{\circ} \mathrm{C}$, individuals of $R$. limacum survived and infected new snails (Schüpbach and Baur, $2008 b$ ). In the present study, none or only very few mites survived in moist soil kept at $4{ }^{\circ} \mathrm{C}$ for 7 months. We found only a single mite egg in 1 out of 60 originally parasite-free snails maintained on these soils. This indicates that 1 mite may have survived in the soil before it could find a new host and deposit the egg in its lung.

The influence of a parasite on its host may change in response to altered physical conditions of the environments. When infected gastropods aestivate, such as during summer droughts, parasite development is normally inhibited (Solomon et al. 1996) and host survival is reduced compared to uninfected snails. Temperature can be a limiting factor on parasite development, both within invertebrate hosts and in free-living parasites. At low temperature, larval development of the nematode Elaphostrongylus rangiferi (Mitskevich 1958) was delayed in the host snails $A$. arbustorum and Euconulus fulvus (MÜLLER 1774) and 1st-stage larvae of this lung worm showed a higher survival than their successive stages in hibernating hosts (Halvorsen and Skorping, 1982; Schjetlein and Skorping, 1995). The minimum temperature necessary for the development of $R$. limacum is not known. However, the number of mites found in the lung tissue was reduced in hosts hibernating for 24 days or longer, while the number of eggs did not change with increasing hibernation duration. In Experiment 2, which had shorter recording intervals, mites did not leave the host when the snails buried in the soil at the beginning of hibernation. However, the number of mites found in the lung tissue decreased when the hosts hibernated for 24 days or longer, while the number of eggs did not change with increasing hibernation duration. Thus, most parasitic mites died and no eggs hatched during hibernation. We frequently observed clumps of white mucus containing dead mites in the respiratory pore of parasitized snails. This could represent a kind of lung cleaning in infected hosts. In spring, when the temperature increases and the host snails emerge from hibernation, the small parasite population might mainly stem from surviving eggs. During the host's activity season the mite population increases, reaching a peak in autumn. This explanation is in line with the seasonal pattern in mite number recorded in $A$. arbustorum and $C$. aspersum (Graham et al. 1996; Baur and Baur, 2005). The seasonal increase in number of mites might depend 
on the temperature and the length of the snail's activity season.

The prevalence of infection by $R$. limacum in populations of $A$. arbustorum is highly variable. In Switzerland, infected populations occurred at localities with a higher mean temperature in June (a surrogate for the length of the vegetation period) than populations without mites (Baur and Baur, 2005). Parasitic mites did not occur in snail populations situated at altitudes of $1290 \mathrm{~m}$ or higher. Climatic factors are known to have a significant effect on the occurrence of helminth parasites in terrestrial gastropods. For example, Morley and Lewis (2008) found a positive correlation between winter maximum temperature and total sporocyst prevalence of trematodes Dicrocoelium sp. in a land snail community in southern England.

Snails are ectothermic animals and are particularly vulnerable to climatic change, not only due to physiological responses but also to a shift in plant community composition and structure impacting on their population dynamics (Baur and Baur, 1993b; Sternberg, 2000). In the temperate zone, global climate change will probably lead to shorter and milder winters, resulting in shorter periods of hibernation. Climate warming may extend the active season of terrestrial gastropods and increase the availability of free-living parasites (Harvell et al. 2002). In the host $A$. arbustorum, hibernation duration may decrease and winter survival of $R$. limacum will increase. The extended active season of the host may allow the parasitic mite to spread to higher altitudes by dispersing snails (Baur and Baur, 1993a).

\section{ACKNOWLEDGEMENTS}

We thank Anette Baur and an anonymous referee for valuable comments on the manuscript. Financial support was received from the Swiss National Foundation.

\section{REFERENCES}

Agnew, P., Koella, J. C. and Michalakis, Y. (2000). Host life history responses to parasitism. Microbes Infections 2, 891-896. doi: 10.1016/S12864579(00)00389-0

Ansart, A., Vernon, P. and Daguzan, J. (2001). Photoperiod is the main cue that triggers supercooling ability in the land snail, Helix aspersa (Gastropoda: Helicidae). Cryobiology 42, 266-73. doi: 10.1006/cryo. 2001.2332

Ansart, A., Vernon, P. and Daguzan, J. (2002). Elements of cold hardiness in a littoral population of the land snail Helix aspersa (Gastropoda: Pulmonata). Fournal of Comparative Physiology B 172, 619-625. doi: 10.1007/s00360-002-0290-z

Baker, R. A. (1970a). The food of Riccardoella limacum (Schrank) (Acari, Trombidiformes) and its relationship with pulmonate molluscs. Fournal of Natural History 4, 521-530. doi: 10.1080/00222937000770481.

Baker, R. A. $(1970 \mathrm{~b})$. Studies on the life history of Riccardoella limacum (Schrank) (Acari, Trombidiformes). Fournal of Natural History 4, 511-519. doi: 10.1080/00222937000770471.

Banhart, M. C. and McMahon, B. R. (1988). Depression of aerobic metabolism and intracellular $\mathrm{pH}$ by hypercapnia in land snails, Otala lactea. Fournal of Experimental Biology 138, 289-299.

Baur, A. and Baur, B. (1993a). Daily movement patterns and dispersal in the land snail Arianta arbustorum. Malacologia 35, 89-98.
Baur, A. and Baur, B. (2005). Interpopulation variation in the prevalence and intensity of parasitic mite infection in the land snail Arianta arbustorum. Invertebrate Biology 124, 194-201. doi: 10.1111/j.1744-7410.2005.00019.x. Baur, B. (1984). Shell size and growth rate differences for alpine populations of Arianta arbustorum (L.) (Pulmonata: Helicidae). Revue suisse de Zoologie 91, 37-46.

Baur, B. (1988). Repeated mating and female fecundity in the simultaneously hermaphroditic land snail Arianta arbustorum. Invertebrate Reproduction and Development 14, 197-204.

Baur, B. (1994). Multiple paternity and individual variation in sperm precedence in the simultaneously hermaphroditic land snail Arianta arbustorum. Behavioral Ecology and Sociobiology 35, 413-421. doi: 10.1007/BF00165844.

Baur, B. and Baur, A. (1993b). Climatic warming due to thermal radiation from an urban area as possible cause for the local extinction of a land snail. Fournal of Applied Ecology 30, 333-340. doi: 10.2307/ 2404635.

Baur, B. and Raboud, C. (1988). Life-history of the land snail Arianta arbustorum along an altitudinal gradient. Fournal of Animal Ecology 57, 71-87. doi: 10.2307/4764.

Callait, M. P. and Gauthier, D. (2000). Parasite adaptations to hibernation in Alpine marmots (Marmota marmota). Life in the Cold: Eleventh International Hibernation Symposium, pp. 139-146. Springer, Berlin, Germany.

Fain, A. and van Goethem, J. L. (1986). Les acariens du genre Riccardoella Berlese 1923 parasites du poumon de mollusques gastéropodes pulmonés terrestres. Acarologia 27, 125-140.

Graham, F. J., Runham, N. W. and Ford, J. B. (1996). Long-term effects of Riccardoella limacum living in the lung of Helix aspersa. British Crop Protection Council Symposium Proceedings 66, 359-364.

Halvorsen, O. and Skorping, A. (1982). The influence of temperature on growth and development of the nematode Elaphostrongylus rangiferi in the gastropods Arianta arbustorum and Euconulus fulvus. Oikos 38, 285-290. doi: $10.2307 / 3544666$.

Harvell, C. D., Mitchell, C. E., Ward, J. R., Altizer, S., Dobson, A. P., Ostfeld, R. S. and Samuel, M. D. (2002). Climate warming and disease risks for terrestrial and marine biota. Science 296, 2158-2162. doi: 10.1126/ science.1063699.

Kerney, M. P. and Cameron, R. A. D. (1979). A Field Guide to the Land Snails of Britain and North-West Europe. Collins, London, UK.

Mitchell, S. E., Rogers, E. S., Little, T. J. and Read, A. F. (2005). Hostparasite and genotype-by-environment interactions: Temperature modifies potential for selection by a sterilizing pathogen. Evolution 59, 70-80. doi: 10.1554/04-526.

Moore, J. (2002). Parasites and the Behavior of Animals. Oxford University Press, Oxford, UK.

Morley, N. J. and Lewis, J.W. (2008). The influence of climatic conditions on long-term changes in the helminth fauna of terrestrial molluscs and the implications for transmission in southern England. Fournal of Helminthology 82, 325-335. doi: 10.1017/S0022149X0802645X.

Poulin, R. (2007). Evolutionary Ecology of Parasites, 2nd Edn. Princeton University Press, Princeton, NJ, USA.

Pulkkinen, K. and Ebert, D. (2004). Host starvation decreases parasite load and mean host size in experimental populations. Ecology 85, 823-833. doi: 10.1890/03-0185.

R Development Core Team (2011). R: A Language and Environment for Statistical Computing, R Foundation for Statistical Computing. URL http:// www.R-project.org, Vienna, Austria.

Schjetlein, J. and Skorping, A. (1995). The temperature threshold for development of Elaphostrongylus rangiferi in the intermediate host: an adaptation to winter survival? Parasitology 111, 103-110. doi: 10.1017/ S0031182000064659.

Schmid-Hempel, P. (1998). Parasites in Social Insects. Princeton University Press, Princeton, NJ, USA.

Schuster, R. (1993). Infection patterns in the first intermediate host of Dicrocoelium dendriticum. Veterinary Parasitology 47, 235-243. doi: 10.1016/ 0304-4017(93)90025-I.

Schüpbach, H. U. and Baur, B. (2008a). Parasitic mites influence fitness components of their host, the land snail Arianta arbustorum. Invertebrate Biology 127, 350-356. doi:10.1111/j.1744-7410.2008.00138.x.

Schüpbach, H.U. and Baur, B. (2008b). Experimental evidence for a new transmission route in a parasitic mite and its mucus-dependent orientation towards the host snail. Parasitology 135, 1679-1684. doi: 10.1016/j.ijpara.2010.02.012.

Schüpbach, H. U. and Baur, B. (2010a). Contact-based transmission models in terrestrial gastropod populations infected with parasitic mites. International Fournal for Parasitology 40, 1045-1050. doi: 10.1016/ j.ijpara.2010.02.012. 
Schüpbach, H. U. and Baur, B. (2010b). Within- and among-family variation in parasite load and parasite-induced mortality in the land snail Arianta arbustorum, a host of parasitic mites. Fournal of Parasitology 96, 830-832. doi: 10.1645/GE-2315.1.

Seppälä, O., Liljeroos, K., Karvonen, A. and Jokela, J. (2008). Host condition as a constraint for parasite reproduction. Oikos 117, 749-753. doi: 10.1111/j.0030-1299.2008.16396.x.

Sheldon, B. C. and Verhulst, S. (1996). Ecological immunology: costly parasite defences and trade-offs in evolutionary ecology. Trends in Ecology \& Evolution 11, 317-321. doi: 10.1016/0169-5347(96)10039-2.
Solomon, A., Paperna, I. and Markovics, A. (1996). The influence of aestivation in land snails on the larval development of Muellerius cf. capillaris (Metastrongyloidea: Protostrongylidae). International fournal for Parasitology 26, 363-367. doi: 10.1016/0020-7519(96)00013-6.

Sternberg, M. (2000). Terrestrial gastropods and experimental climate change: a field study in a calcareous grassland. Ecological Research 15, 73-81. doi: 10.1046/j.1440-1703.2000.00327.x.

Tyler, B. M. J. and Jones, P. A. (1974). Hibernation study with Lysiphlebus testaceipes, parasite of the greenbug. Environmental Entomology 3, 412-414 